\title{
New Conductometric Titration Methods for Determination of Diphenhydramine Hydrochloride Using Sodium Tetraphenylborate and Cetylpyridinium Bromide
}

\author{
Safwan Ashour ${ }^{*}$, Haitham Aboudan \\ Analytical Chemistry Laboratory, Department of Chemistry, Faculty of Sciences, University of Aleppo, Aleppo, Syria
}

Email address:

profashour@hotmail.com (S. Ashour)

*Corresponding author

\section{To cite this article:}

Safwan Ashour, Haitham Aboudan. New Conductometric Titration Methods for Determination of Diphenhydramine Hydrochloride Using Sodium Tetraphenylborate and Cetylpyridinium Bromide. International Journal of Pharmacy and Chemistry. Vol. 4, No. 1, 2018, pp. 8-15. doi: $10.11648 /$ j.ijpc.20180401.12

Received: January 15, 2018; Accepted: January 31, 2018; Published: February 26, 2018

\begin{abstract}
Sodium tetraphenylborate (TPB) and cetylpyridinium bromide (CPB) were used as titrant for the conductometric determination of diphenhydramine hydrochloride (DPH) drug through ion association complex formation and then the conductance of the solution is measured as a function of the volume of titrant. The effect of the solvent, reagent concentration, temperature and molar combining ratio of the formed ion-associates were studied and evaluated. The suggested method was applied for the determination of diphenhydramine hydrochloride in pure form and pharmaceutical preparations. The described procedures allowed the determination of the studied drug in bi-distilled water in the range of $0.75-16 \mathrm{mg}$. Statistical treatment of the experimental results indicates that the method is precise and accurate. The accuracy of the method was indicated by excellent recovery and the precision supported by the low relative standard deviation $<1 \%$. The sensitivity of the proposed method was discussed and the results were compared with the potentiometric pharmacopoeial method. The proposed procedure was simple, precise and low cost and can be applied for the routine measurements of the cited drug.
\end{abstract}

Keywords: Diphenhydramine Hydrochloride, Sodium Tetraphenylborate, Cetylpyridinium Bromide, Conductometry, Pharmaceutical Formulations

\section{Introduction}

Diphenhydramine hydrochloride (DPH), 2(diphenylmethoxy)-N, N-dimethylethylamine hydrochloride, is a histamine H1-receptor antagonist and is widely used as antiallergic, antiemetic and antitussive drug found in many pharmaceutical preparations. It is usually given orally in a preparation of tablet, capsule or syrup. It may be administered by intramuscular or intravenous injection in severe allergies and applied topically for local allergic reactions in preparations of lotion and cream containing 1$2 \%$ [1, 2]. Several methods have been reported for determination of diphenhydramine hydrochloride in pharmaceutical formulations including spectrophotometry [3-10], flow injection spectrophotometry [11, 12], atomic absorption spectrometry [13-16], potentiometry with selective membrane electrode [17-19], non-aqueous potentiometric titration [20], amperometry [21], capillary electrophoresis [22-26] and conductometric titration using silver nitrate as a titrant [27]. Chromatographic methods have been used for the determination of diphenhydramine hydrochloride with other ingredients in combined formulations including high performance liquid chromatography with UV detection [28-36], indirect conductometric detection [37], gas chromatography [38-42] and high-performance thin layer chromatography [43, 44]. The drug and its formulations are official in British Pharmacopoeia [45], which recommended HPLC for its assay.

The aim of this work was to report new condutometric methods that are simple, time-saving and accurate for the determination of diphenhydramine hydrochloride as a raw material and in some pharmaceutical preparations with no interference of other constituents in their formulations. 


\section{Experimental}

\subsection{Instrumentation}

A conductometer-Crison C525 (Spain) equipped with conductivity cell (cell constant of 0.95) -Ingold (Swiss) was used. The measurement ranges were $0-2000 \mu \mathrm{s} / \mathrm{cm}$ and 0 $200 \mathrm{~ms} / \mathrm{cm}$ with a precision $\pm 0.05 \%$. $\mathrm{pH}$ meter-Suntex SP-5 (Taiwan) equipped with combined glass $\mathrm{pH}$ electrodeConsort S201 B LL5 (Belgium), analytical balance- Sartorius 2432 with a precision $\pm 0.1 \mathrm{mg}$ and circulating water-bath thermostat-MLW U10 (Germany) were used. The temperature was maintained at $25 \pm 5^{\circ} \mathrm{C}$ with water-bath thermostat connected to a jacket around the analysis vessel.

\subsection{Materials}

All chemicals used throughout this work were of analytical-reagent grade and solutions were made with bidistilled water. Diphenhydramine hydrochloride (DPH) was obtained from Dolder, Swiss; its purity was found to be $99.89 \%$ according to BP [41]. Sodium tetraphenylborate (TPB) was obtained from Aldrich and cetylpyridinium bromide (CPB) was obtained from $\mathrm{BDH}$. Methanol and ethanol (Merck) were also used. Kartastamine tablets (Shah Co., Syria) was purchased from commercial sources in the local market, labeled to contain $25 \mathrm{mg}$ diphenhydramine hydrochloride per tablet.

\subsection{Solutions}

Solutions $1 \times 10^{-2} \mathrm{M}$ of TPB and CPB were prepared by dissolving the appropriate weight in bi-distilled water. The solution was standardized and kept in light-resistant, wellclosed container. Aqueous solution of $1 \mathrm{mg} \mathrm{mL}$ diphenhydramine hydrochloride was prepared by dissolving $100 \mathrm{mg}$ of the pure drug in $100 \mathrm{~mL}$ bi-distilled water, stored in dark bottles and kept in the refrigerator for not more than 10 days. Other concentrations of working solutions were then prepared by suitable dilution of the stock solution with bidistilled water.

\subsection{General Procedure}

Aliquots of standard solution containing $0.75-16 \mathrm{mg}$ of DPH were transferred into a $25 \mathrm{~mL}$ calibrated flasks and made up to the mark with bi-distilled water. The contents of the calibrated flask were transferred quantitatively to a conductometric titration cell, the conductivity cell was immersed in the sample solution, the solution was then titrated conductometrically against $1 \times 10^{-2} \mathrm{M}$ TPB or CPB and the conductance was measured subsequent to each addition of the reagent solution and after thorough stirring for three min. The conductance reading was corrected for dilution [46] by means of the equation (1), assuming that conductivity is a linear function of dilution.

$$
\Omega^{-1}{ }_{\text {correct }}=\Omega^{-1}{ }_{\text {obs }}\left[\mathrm{V}_{1}+\mathrm{V}_{2} / \mathrm{V}_{1}\right]
$$

where $\Omega^{-1}$ correct is the corrected electrolytic conductivity, $\Omega$ ${ }_{\text {obs }}$ is the observed electrolytic conductivity, $\mathrm{V}_{1}$ is the initial volume and $\mathrm{V}_{2}$ is the volume of reagent added.

A graph of corrected conductivity versus the volume of added titrant was constructed and the end point was determined conductometrically.

The amount of drugs under study was calculated according to the equation (2),

$$
\text { Amount of drug }=\text { V. M. R/N }
$$

where $\mathrm{V}$ is volume $(\mathrm{mL})$ of titrant, $\mathrm{M}$ is molecular weight of drug, $\mathrm{R}$ is molar concentration of titrant and $\mathrm{N}$ is number of moles of titrant consumed by one mole of drug.

\subsection{Procedure for the Pharmaceutical Dosage Forms}

Twenty tablets were weighed and finely powdered. An accurately weighed quantity of the powder equivalent to 100 $\mathrm{mg}$ of drug was dissolved in $50 \mathrm{~mL}$ of methanol and sonicated for 5 minutes and then filtered. The combined filtrate was evaporated to the dryness. The remaining portion of the solution was dissolving with bi-distilled water in a 100 $\mathrm{mL}$ volumetric flask and diluted to the volume. The resulting solution was used for analysis by the recommended procedures in the concentration ranges mentioned above.

\section{Results and Discussion}

Conductometric measurements can be used in quantitative titration of ionic solutions in which the conductance of the solution varies before and after the equivalence point, so that two intersecting lines can be drawn to indicate the end point. The shape of the titration curve depends on all the species present during the titration process and other factors such as viscosity, dielectric constant of the solvent used, solvation, ion-pair association and proton transfer. Diphenhydramine hydrochloride is able to form precipitates with sodium tetraphenylborate or cetylpyridinium bromide so the applicability of conductometric titration of this drug with the mentioned reagents was tested. The different parameters affecting the end point, such as solvent, temperature and concentration of both titrant and titrand, were studied.

\subsection{Effect of Solvent}

Three different titrations were described for the drug: (i) aqueous solutions of both drug and reagents, (ii) methanolic solutions of both drug and reagents and (iii) ethanolic solutions of both drug and reagents at $25^{\circ} \mathrm{C}$. It was found that procedure (i) in aqueous media was the most suitable for successful results as shown in Figure 1, because in procedures (ii) and (iii) the end point detection is very difficult and so the precision is very low, whereas in water medium sharpest end point was detected. So water was the best and cheapest choice medium for conductometric titration. 

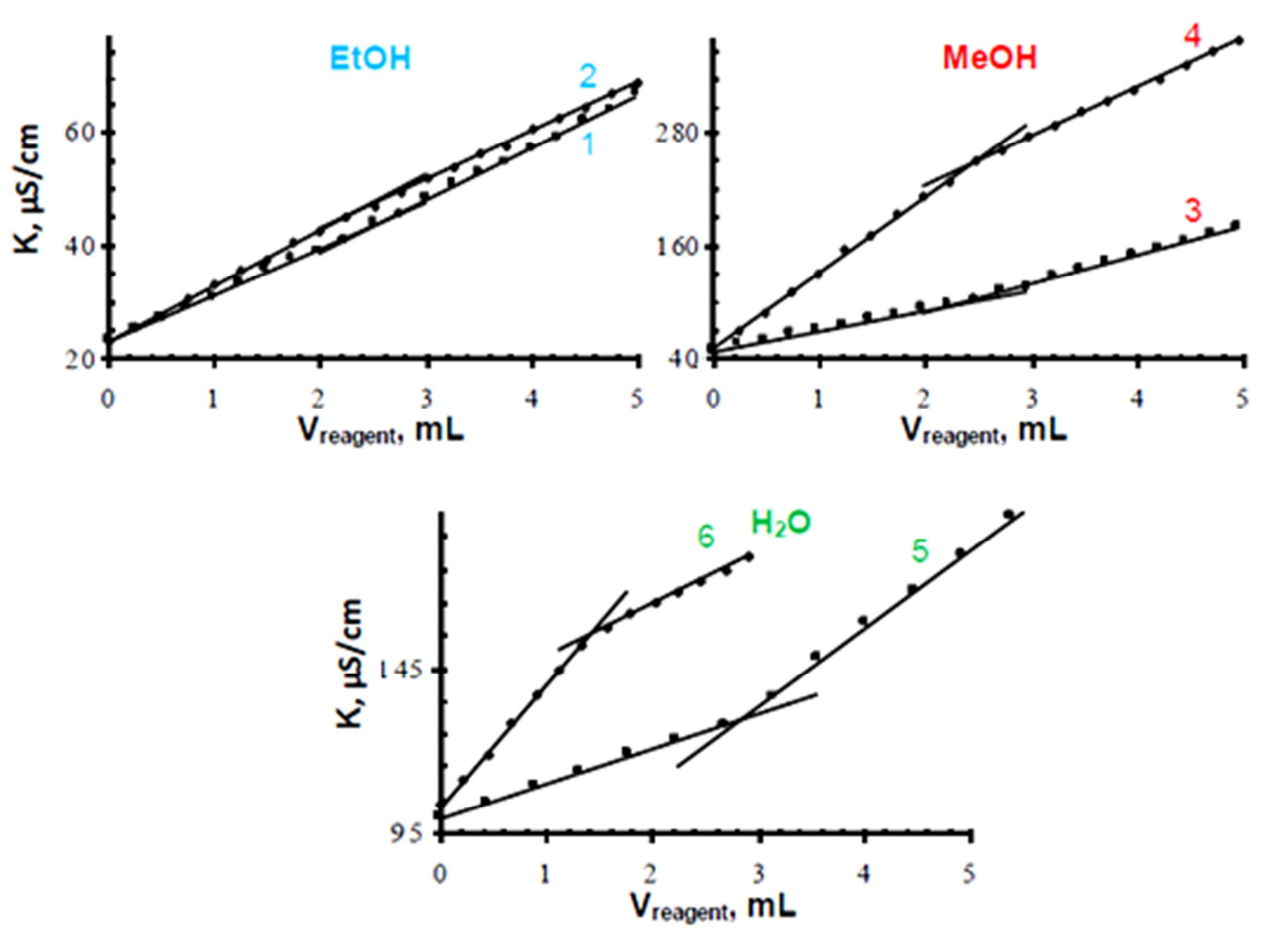

Figure 1. The effect of solvent on the shape of end point for the conductometric titration of $8 \mathrm{mg}$ DPH in total volume $25 \mathrm{~mL}$ with $1 \times 10^{-2} \mathrm{M} \mathrm{TPB}(1,3,5)$ and with $1 \times 10^{-2} M C P B(2,4,6)$ at $25^{\circ} \mathrm{C}$.

\subsection{Effect of Temperature}

The relation between the conductance values and temperature of $\mathrm{DPH}, \mathrm{CPB}$ and $\mathrm{TPB}$ solutions was linear increasing in aqueous media in the range of $20-60^{\circ} \mathrm{C}$. The effect of temperature on the end point of the conductometric titration was tested by carrying out titrations at $20-60^{\circ} \mathrm{C}$. The results showed that as the temperature increases, the conductivity of the whole solution increases, and no effect was observed on the shape of the titration curve and the position of the end point up to $40^{\circ} \mathrm{C}$, then $25^{\circ} \mathrm{C}$ was used for carrying out the other variables.

\subsection{Effect of Reagent Concentration}

The relationship between the conductance values and the concentration of DPH, TPB and CPB solutions was linear increasing in the range of $0.05-10 \mathrm{mM}$ in aqueous medium as shown in Figure 2. The conductance value of DPH solution was greater than that for TPB and CPB solution at the same concentration with about one and two times, respectively. The effect of electrolyte concentration on the specific electrical conductivity was studied and indicated that the values were decreased as follows $\mathrm{DPH}<\mathrm{TPB}<\mathrm{CPB}$ in aqueous medium.

A weight of the investigated drug $7.30 \mathrm{mg}$ of DPH was dissolved in $25 \mathrm{~mL}$ bi-distilled water was titrated against $1 \times 10^{-3}, 5 \times 10^{-3}$ and $1 \times 10^{-2} \mathrm{M}$ TPB or CPB solutions. The results indicated that, titrant solutions lower than $1 \times 10^{-2} \mathrm{M}$ are not suitable for conductometric titrations as the conductance readings were unstable and the inflection at the end point was very poor. So, the reagent concentration in each titration must be not less than ten times that of the drug solution in order to minimize the dilution effect on the conductivity throughout the titration. The optimum concentration of TPB and CPB was $1 \times 10^{-2} \mathrm{M}$ to achieve a constant and highly stable conductance reading after 1 minute mixing. On the other hand, when the same above mentioned amounts of the investigated drug were dissolved and diluted up to 25,50 and $75 \mathrm{~mL}$ with bi-distilled water and titrated against $1 \times 10^{-2} \mathrm{M}$ TPB or CPB solution (optimum titrant concentration). The results showed that, dilution of the titrand up to $75 \mathrm{~mL}$ has no effect on the position of the end point and the shape of the titration curve.

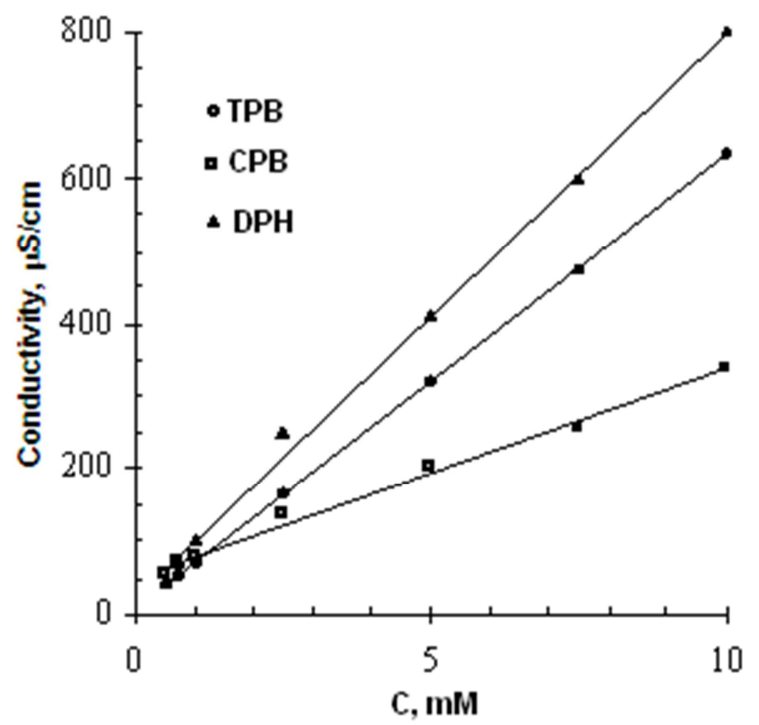

Figure 2. The effect of electrolyte concentration on the conductivity in double distilled water 


\subsection{Determination of the Drug-Titrant Ratio}

The conductometric technique was used for the determination of DPH using TPB and CPB as titrants; the ion associates are formed between the studied drug and titrant as shown in Figure 3.<smiles>CN(C)CCOC(c1ccccc1)c1ccccc1</smiles>

Diphenhydramine. $\mathrm{HCl}$

TPB<smiles>CN(C)CCOC(c1ccccc1)c1ccccc1</smiles>

Diphenhydramine. $\mathrm{H}\left[\mathrm{B}\left(\mathrm{C}_{6} \mathrm{H}_{5}\right)_{4}\right]$

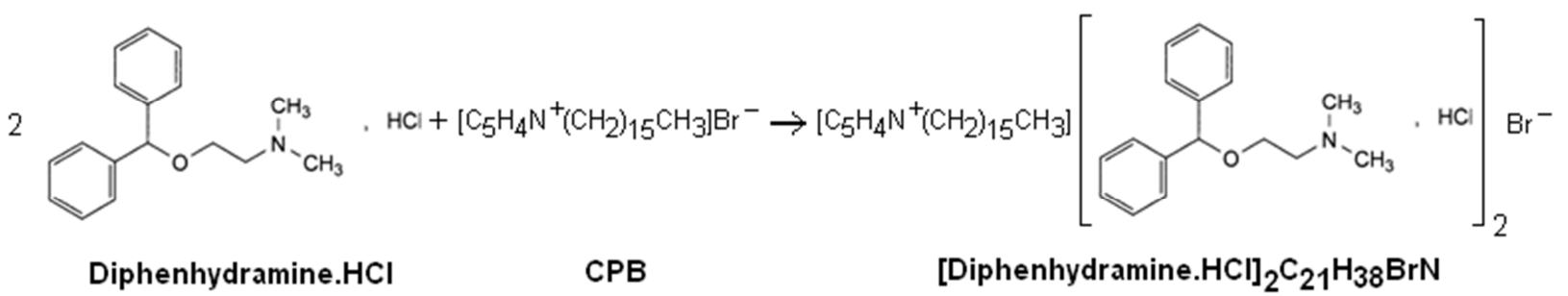

Figure 3. The probable reaction of formation of the ion association complexes.

The investigated systems showed two straight lines are obtained, intersecting at the end-point. In the case of CPB, the titration curve showed a steady increase in conductance values up to the equivalence point where a sudden change in the slope occurs. In the case of TPB, the first branch gradually increases and the second sharply ascending. This divergence from linearity can be attributed to the formation of an ion-associate, presumably, by replacing the drug cation $\left(\mathrm{DPH} . \mathrm{H}^{+}\right)$with the highly mobile $\mathrm{Na}^{+}$ions and formation of alkali halide in the solution as a result of the reaction, so the conductivity increases. After the end point, more $\mathrm{Na}^{+}$reagent is added and the conductivity changes more rapidly as shown in Figure 4.

The increase of conductance may be attributed to the formation of more stable DPH. H $\left[\mathrm{B}\left(\mathrm{C}_{6} \mathrm{H}_{5}\right)_{4}\right]$ complex in the solution as a result of the reaction. After the end-point, more $\mathrm{Na}^{+}$reagent is added, the titration curve indicate a sharply increase of conductance. The results show an obvious inflection point in the conductance titration curve at drugreagent molar ratio of 1:1 and 2:1 (DPH: TPB and DPH: $\mathrm{CPB}$ ) as shown in Figure 4. Figure 5 summarizes the change of each species during the conductometric titration of DPH versus $\mathrm{TPB}$ or $\mathrm{CPB}$ at $25^{\circ} \mathrm{C}$ and the sum titration curve.

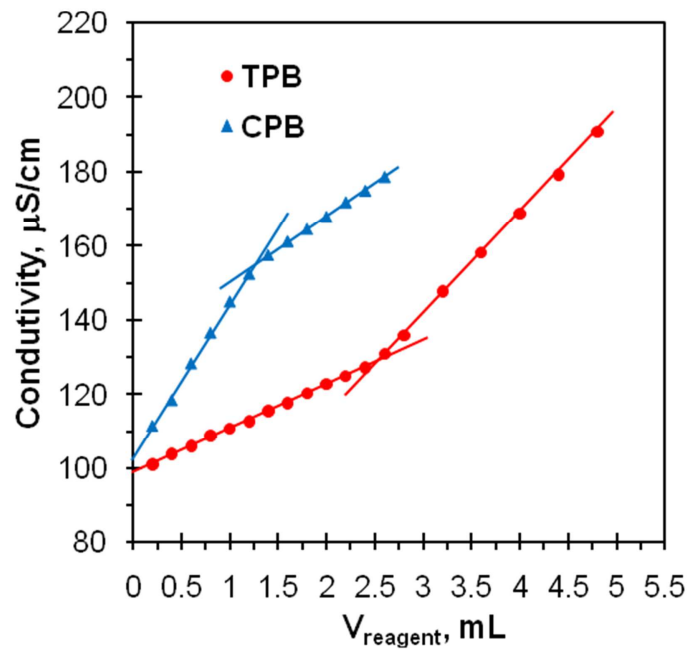

Figure 4. Conductometric titration curves of $7.30 \mathrm{mg}$ DPH versus $1 \times 10^{-2} \mathrm{M}$ $T P B$ or $C P B$ at $25^{\circ} \mathrm{C}$.

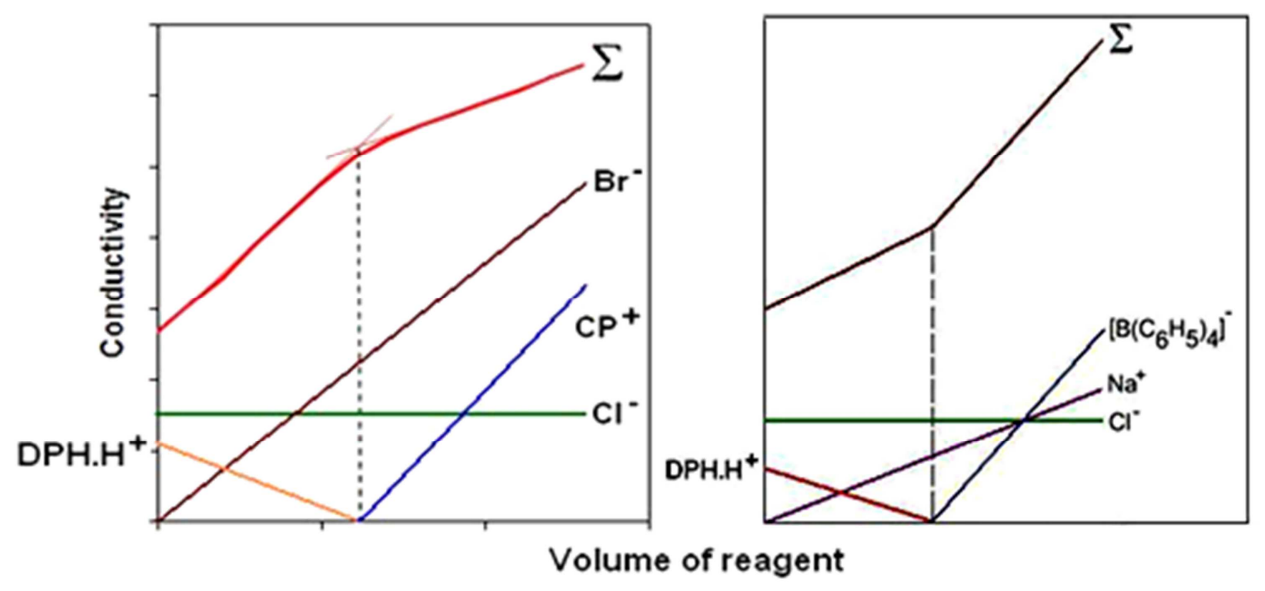

Figure 5. Species change during the conductometric titration of DPH versus $T P B$ or $C P B$ at $25^{\circ} \mathrm{C}$. 


\subsection{Linearity}

The optimum concentration range for determining DPH using TPB and CPB was $0.03-0.64 \mathrm{mg} \mathrm{mL}^{-1}$, at which welldefinite inflections and stable conductance values were obtained. In order to establish whether the proposed method exhibits any fixed or proportional bias, a simple linear regression [47] of observed drug concentration against the theoretical values ( 5 points) was calculated. Student's t-test (at $95 \%$ confidence level) was applied to the slope of the regression line (Table 1) and showed that it did not differ significantly from the ideal value of unity. Hence, it can be concluded that there are no systematic differences between the determined and true concentrations over the cited range. The standard deviation (SD) can be considered satisfactory, at least for the level of concentrations examined.

Table 1. Linear regression analysis for DPH using TPB and CPB.

\begin{tabular}{lll}
\hline Parameters & CPB & TPB \\
\hline Optimum concentration range $\left(\mathrm{mg} \mathrm{mL}^{-1}\right)$ & $0.03-0.64$ & \\
Intercept of the regression line $^{\mathrm{a}}$ & 1.202 & 1.106 \\
Slope of regression line & 1.007 & 0.996 \\
Student's t $^{\mathrm{b}}(2.310)^{\mathrm{c}}$ & 1.723 & 1.548 \\
Range of error $(\%)^{\mathrm{R}} \mathrm{n}$ & \pm 0.69 & \pm 0.52 \\
\hline
\end{tabular}

${ }^{a}$ Observed versus theoretical. ${ }^{\mathrm{b}}$ Comparison with pharmacopoeial method [41]. ${ }^{\mathrm{c}}$ Value in parenthesis is the theoretical t-value for five degrees of freedom.

\subsection{Validation of the Methods}

The validity of the method for the analysis of DPH in pure state and formulations was examined by analyzing the samples using the proposed procedures. The results obtained for the pure drug are given in Table 2 and show that good recovery and standard deviation were obtained. The precision and accuracy of the methods were tested by analyzing six replicates of the drug. The low values of the relative standard deviation (RSD\%) indicate good precision and reproducibility of the methods and the average percent recoveries obtained were quantitative, indicating good accuracy of the methods.

\subsection{Application to the Pharmaceutical Dosage Forms}

The proposed technique was applied to the tablets. The ingredients in the tablets did not interfere in the experiments. The applicability of the proposed methods for the assay of DPH in formulations was examined by analyzing formulation and the results are tabulated in Table 3 were compared to the official non-aqueous titration method [45] by means of $t$ - and $F$-values at $95 \%$ confidence level. In all cases, the average results obtained by proposed and official methods were statistically identical, as the difference between the average values had no significance at $95 \%$ confidence level. The low values of $\mathrm{RSD} \%$ show the results are reproducible. The proposed methods are simple, sensitive and reproducible and can be used for routine analysis of DPH in pure form and in formulations. The commonly used additives such as starch, lactose, glucose and titanium dioxide do not interfere.

Table 2. Conductometric titration of DPH using TPB and CPB.

\begin{tabular}{|c|c|c|c|c|c|c|}
\hline \multirow{3}{*}{ Method } & \multicolumn{3}{|l|}{ CPB } & \multicolumn{3}{|l|}{ TPB } \\
\hline & Taken & Found & Recovery & Taken & Found & Recovery \\
\hline & (mg) & (mg) & $(\%)$ & (mg) & (mg) & $(\%)$ \\
\hline \multirow{6}{*}{ Parameters } & 0.750 & 0.746 & 99.48 & 0.750 & 0.748 & 99.83 \\
\hline & 3.000 & 3.012 & 100.39 & 3.000 & 3.031 & 101.03 \\
\hline & 6.000 & 5.980 & 99.67 & 6.000 & 6.010 & 100.17 \\
\hline & 9.000 & 9.041 & 100.46 & 9.000 & 9.036 & 100.40 \\
\hline & 12.000 & 12.015 & 100.13 & 12.000 & 12.079 & 100.66 \\
\hline & 16.000 & 16.064 & 100.40 & 16.000 & 16.075 & 100.47 \\
\hline Mean \pm SD & \multicolumn{3}{|l|}{$100.18 \pm 0.954$} & \multicolumn{3}{|l|}{$100.50 \pm 0.931$} \\
\hline $\mathrm{N}$ & \multicolumn{3}{|l|}{6} & \multicolumn{3}{|l|}{6} \\
\hline V & \multicolumn{3}{|l|}{0.910} & \multicolumn{3}{|l|}{0.867} \\
\hline $\mathrm{RSD} \%$ & \multicolumn{3}{|l|}{0.952} & \multicolumn{3}{|l|}{0.926} \\
\hline SE & \multicolumn{3}{|l|}{0.086} & \multicolumn{3}{|l|}{0.409} \\
\hline
\end{tabular}

* SD: Standard deviation; N: number of experiments; V: Variance; RSD: Relative standard deviation; SE: Standard error.

Table 3. Conductometric determination of DPH in tablet dosage form using TPB and CPB.

\begin{tabular}{lllllllllll}
\hline \multicolumn{1}{l}{ Diphenhydramine hydrochloride (Kartastamine tablets) } \\
\cline { 2 - 10 }
\end{tabular}




\begin{tabular}{|c|c|c|c|c|c|c|c|c|c|c|c|c|}
\hline \multirow{4}{*}{ Drug } & \multicolumn{12}{|c|}{ Diphenhydramine hydrochloride (Kartastamine tablets) } \\
\hline & \multicolumn{4}{|c|}{ TPB method } & \multicolumn{4}{|c|}{ CPB method } & \multicolumn{4}{|c|}{ Official method } \\
\hline & Taken & Added & Found & Recovery & Taken & Added & Found & Recovery & Taken & Added & Found & Recovery \\
\hline & (mg) & & & $(\%)$ & (mg) & & & $(\%)$ & (mg) & & & $(\%)$ \\
\hline RSD $\%$ & 0.85 & & & & 0.76 & & & & 0.92 & & & \\
\hline t-test & 1.75 & & & & 2.09 & & & & 1.90 & & & \\
\hline F-test & 1.20 & & & & 1.46 & & & & - & & & \\
\hline
\end{tabular}

Mean and SD of five determinations.

F-tabulated is 6.26 at $95 \%$ confidence limit and t-tabulated is 2.776 at 95 confidence limit.

\section{Conclusion}

The simple, rapid and accurate conductometric method described in this paper can be an alternative to the more complex and expensive methods for the assay of diphenhydramine hydrochloride without interference from common excipients. The proposed method is easy, cheap, accurate and very useful for the determination of the studied drug in its pharmaceutical formulation and can be applied in laboratories for routine analysis. The developed method for diphenhydramine hydrochloride is higher sensitivity as compared to similar reported method.

\section{References}

[1] Sweetman Sean C. (2011). Martindale. The Complete Drug Reference $37^{\text {th }}$ ed., London, England, UK: Pharmaceutical Press.

[2] Gennaro A. R. (1995). In: Remington: The Science and Practice of Pharmacy, Mack Publishing Company, Pennsylvania, 1225-1226.

[3] Devrim B., Dinç E., Bozkir A. (2014). Fast determination of diphenhydramine hydrochloride in reconstitutable syrups by CWT, PLS and PCR methods. Acta Poloniae PharmaceuticaDrug Research 71 (5), 721-729.

[4] Al Bratty M. (2016). Visible spectrophotometric determination of chlorpheniramine maleate and diphenhydramine hydrochloride in raw and dosage form using potassium permanganate. Oriental Journal of Chemistry 32 (2), 885-894.

[5] Goicoechea H. C., Olivieri A. C. (2002). Chemometric assisted simultaneous spectrophotometric determination of four-component nasal solutions with a reduced number of calibration samples. Analytica Chimica Acta, 453 (2), 289300 .

[6] Basavaiah K., Charan V. S. (2002). Titrimetric and spectrophotometric assay of some antihistamines through the determination of the chloride of their hydrochlorides. IL Farmaco 57 (1), 9-17.

[7] Souri E., Rahimi A., Shabani Ravari N., Tehrani M. B. (2015). Development of a rapid derivative spectrophotometric method for simultaneous determination of acetaminophen, diphenhydramine and pseudoephedrine in tablets. Iranian Journal of Pharmaceutical Research 14 (2), 435-442.

[8] El-Didamony A. M., Moustafa M. A. (2010). Spectrophotometric determination of diphenhydramine hydrochloride in pharmaceutical preparations and biological fluids via ion-pair formation. Arabian Journal of Chemistry 3 (4), 265-270.

[9] Ulu S. T., Elmali F. T. (2010). Spectrophotometric method for the determination, validation, spectroscopic and thermal analysis of diphenhydramine in pharmaceutical preparation. Spectrochimica Acta Part A 77 (1), 324-329.

[10] Hassan W. S., El-Henawee M. M., Gouda A. A. (2008). Spectrophotometric determination of some histamine H1antagonists drugs in their pharmaceutical preparations. Spectrochimica Acta Part A 69 (1), 245-255.

[11] Tipparat P., Lapanantonppakhun S., Jakmunee J., Grudpan K. (2002). Determination of diphenhydramine hydrochloride in some single tertiary alkylamine pharmaceutical preparations by flow injection spectrophotometry. Journal of Pharmaceutical and Biomedical Analysis 30 (1), 105-112.

[12] Martinez Calatayud J., Sanchez Sampedro A., Navasquillo Sarrion S. (1990). Determination of diphenhydramine hydrochloride by flow injection with bromophenol blue and turbidimetric measurement. Analyst 115 (6), 855-858.

[13] Nerin C., Garnica A., Cacho J. (1986). Analysis of drugs by AAS via formation of ion pairs. Mikrochimica Acta 3 (1-2), $117-126$.

[14] Nerin C., Cacho J., Garnica A. (1993). Indirect determination of diphenhydramine hydrochloride by atomic absorption spectrometry. Journal of Pharmaceutical and Biomedical Analysis 11 (4-5), 411-414.

[15] El Ries M. A., Khalil S. (2001). Indirect atomic absorption determination of atropine, diphenhydramine, tolazoline, and levamisole based on formation of ion-associates with potassium tetraiodometrcurate. Journal of Pharmaceutical and Biomedical Analysis 25 (1), 3-7.

[16] Khalil S. (1999). Atomic emission spectrometric determination of ephedrine, cinchonine, chlorpheniramine, atropine, and diphenhydramine based on formation of ion associates with ammonium reineckate. Journal of Pharmaceutical and Biomedical Analysis 21 (4), 697-702.

[17] Shoukry A. F., Badawy S. S., Issa Y. M. (1987). Diphenhydramine-sensitive membrane electrodes based on poly (vinylchloride) matrices and their use in drug analysis. Journal of Electroanalytical Chemistry 233 (1-2), 29-36.

[18] Erdem A., Ozsoz M., Kirilmaz L., Kilinc E., Dalbasti T. (1997). Diphenhydramine-selective plastic membrane sensor and its pharmaceutical applications. Electroanalysis 9 (12), 932-935.

[19] Frag E. Y. Z., Mohamed G. G., El-Sayed W. G. (2011). Potentiometric determination of antihistaminic diphenhydramine hydrochloride in pharmaceutical preparations and biological fluids using screen-printed electrode. Bioelectrochemistry 82 (2), 79-86. 
[20] Evstratova K. I., Bakholdina L. A. (1990). Use of propylene carbonate and its mixtures with acetic anhydride in the analysis of drugs. Farmatsiya (Moscow) 39 (4), 62-64.

[21] Freitas J. M., Oliveira Tda C., Gimenes D. T., Munoz R. A., Richter E. M. (2016). Simultaneous determination of three species with a single-injection step using batch injection analysis with multiple pulse amperometric detection. Talanta $146,670-675$.

[22] Gomez M. R., Olsina R. A., Martínez L. D., Silva M. F. (2002). Simultaneous determination of dextromethorphan, diphenhydramine and phenylephrine in expectorant and decongestant syrups by capillary electrophoresis. Journal of Pharmaceutical and Biomedical Analysis 30 (15), 791-799.

[23] Marchesini A. F., Williner M. R., Mantovani V. E., Robles J. C., Goicoechea H. C. (2003). Simultaneous determination of naphazoline, diphenhydramine and phenylephrine in nasal solutions by capillary electrophoresis. Journal of Pharmaceutical and Biomedical Analysis 31 (1), 39-46.

[24] Gomez M. R., Sombra L., Olsina R. A., Martínez L. D., Silva M. F. (2005). Development and validation of a capillary electrophoresis method for the determination of codeine, diphenhydramine, ephedrine and noscapine in pharmaceuticals. IL Farmaco 60 (1), 85-90.

[25] Dong Y., Chen X., Chen Y., Chen X., Hu Z. (2005). Separation and determination of pseudoephedrine, dextromethorphan, diphenhydramine and chlorpheniramine in cold medicines by nonaqueous capillary electrophoresis. Journal of Pharmaceutical and Biomedical Analysis 39 (1-2), 285-289.

[26] Liu J., Cao W., Yang X., Wang E. (2003). Determination of diphenhydramine by capillary electrophoresis with tris $\left(2,2^{\prime}-\right.$ bipyridyl) ruthenium (II) electrochemiluminescence detection. Talanta 59 (3), 453-459.

[27] Al Bratty M., Hashem H., Noureldeen A., Manoharan G., Towhari F. (2015). Conductometric determination of the antihistaminic diphenhydramine hydrochloride using silver nitrate as a titrant, International Journal of Pharmacy and Pharmaceutical Sciences, 7 (3), 72-76.

[28] Ali M. S., Ghori M., Rafiuddin S., Khatri A. R. (2007). A new hydrophilic interaction liquid chromatographic (HILIC) procedure for the simultaneous determination of pseudoephedrine hydrochloride (PSH), diphenhydramine hydrochloride (DPH) and dextromethorphan hydrobromide (DXH) in cough-cold formulations. Journal of Pharmaceutical and Biomedical Analysis 43 (1), 158-167.

[29] Gil-Agustí M., Monferrer-Pons L., Esteve-Romero J., GarcíaAlvarez-Coque M. C. (2001). Quantitation of antihistamines in pharmaceutical preparations by liquid chromatography with a micellar mobile phase of sodium dodecyl sulfate and pentanol. Journal of AOAC International 84 (6), 1687-1694.

[30] Gil-Agustí M., Monferrer-Pons L., García-Alvarez-Coque M. C., Esteve-Romero J. (2001). Determination of active ingredients in cough-cold preparations by micellar liquid chromatography. Talanta 54 (4), 621-630.

[31] Vasudevan M., Ravisankar S., Sathiyanarayanan A., Chandan R. S. (2000). Simultaneous estimation of phenylpropanolamine $\mathrm{HCl}$, guaiphenesin and diphenylpyraline $\mathrm{HCl}$ in syrups by LC. Journal of Pharmaceutical and Biomedical Analysis 24 (1), 25-31.
[32] Martínez-Algaba C., Bermúdez-Saldaña J. M., VillanuevaCamañas R. M., Sagrado S., Medina-Hernández M. J. (2006). Analysis of pharmaceutical preparations containing antihistamine drugs by micellar liquid chromatography. Journal of Pharmaceutical and Biomedical Analysis 40 (2), 312-321.

[33] Turak F., Güzel R., Dinç E. (2016). A new UPLC approach for the simultaneous quantitative estimation of four compounds in a cough syrup formulation. Journal of Chromatographic Science 54 (1), 28-35.

[34] Al Bratty M., Manoharan G. (2016). Simultaneous estimation of diphenhydramine hydrochloride and naproxen sodium in raw and tablet formulation by reverse phase-high-performance liquid chromatographic method, International Research Journal of Pure \&Applied Chemistry, 13 (2), 1-9.

[35] Dönmez Ö. A., Aşçı B., Bozdoğan A., Sungur S. (2011). Simultaneous determination of potassium guaiacolsulfonate, guaifenesin, diphenhydramine $\mathrm{HCl}$ and carbetapentane citrate in syrups by using HPLC-DAD coupled with partial least squares multivariate calibration. Talanta 83 (5), 1601-1605.

[36] Rao D. D., Sait S. S., Mukkanti K. (2011). Development and validation of an UPLC method for rapid determination of ibuprofen and diphenhydramine citrate in the presence of impurities in combined dosage form. Journal of Chromatographic Science 49 (4), 281-286.

[37] Lau I. W., Mok C. S. (1995). High-performance liquidchromatographic determination of active ingredients in cough-cold syrups with indirect conductometric detection. Journal of Chromatography A 693 (1), 45-54.

[38] Abramenko L. L., Aristov G. N., Ischenko V. I. (1988). Gas chromatographic determination of demidrol in dosage forms. Khimiko-Farmatsevticheskii Zhurnal 22 (8), 1014-1016.

[39] Mochizuki E., Yamada I., Komiyama Y., Nakayama A. (1988). Determination of l-mentol, dl-camphor, methyl salicylate and diphenhydramine hydrochloride in ointments by gas chromatography. Yamanashi-ken Eisei Kogai Kenkyusho Nenpo 32, 5-8.

[40] Lau I. W., Cheung Y. M. (1990). Simultaneous determination of some active ingredients in cough-cold syrups by gaschromatography. Analyst (London) 115 (10), 1349-1353.

[41] Raj S. V., Kapadia S. U., Argekar A. P. (1998). Simultaneous determination of pseudoephedrine hydrochloride and diphenhydramine hydrochloride in cough syrup by gas chromatography (GC). Talanta 46 (1), 221-225.

[42] Yao R., Xu Q., Du L. (2007). Direct determination of four components in compound paracetamol and diphenhydramine tablets by wide bore capillary gas chromatography. Sepu 25 (2), 258-261.

[43] Bober K. (2017). Application of HPTLC with densitometry for evaluation of the impact of external factors on contents of diphenhydramine in its solutions, International Journal of Analytical Chemistry, 2017, 1-6.

[44] Bhole R. P., Shinde S. S., Chitlange S. S., Wankhede S. B. (2015). A high-performance thin layer chromatography (HPTLC) method for simultaneous determination of diphenhydramine hydrochloride and naproxen sodium in tablets. Analytical Chemistry Insights, 10, 47-51.

[45] The British Pharmacopœia, London, Her Majesty's, The Stationery Office, 2013. 
[46] Lingane J. J. (1958). Practical Pharmaceutical Chemistry In: Electroanalytical Chemistry. $2^{\text {nd }}$ ed., Interscience, New York, 90.
[47] Miller J. C., Miller J. N. (1993). Statistics in Analytical Chemistry. $3^{\text {rd }}$ ed., Ellis Horwood, Chichester, London. 